lung cancer; 2 via the general chest clinics and 1 following re-referral with persistent haemoptysis.

Conclusion We have shown that almost a quarter of RALC referrals did not adhere to strict referral protocols and would have been better served by a more appropriate referral elsewhere. We are working to educate our primary and secondary care colleagues to ensure that the only appropriate cases are referred to the RALC in order to reap the maximum benefit from this resource intensive service.

\section{P231 AUDIT OF PRE-HOSPITAL OXYGEN THERAPY BY NORTH WEST AMBULANCE SERVICE (NWAS) 1 YEAR AFTER PUBLICATION OF NEW JRCALC GUIDANCE FOR OXYGEN USE}

doi:10.1136/thx.2010.151068.32

A Matthews, C Gavin, B R O'Driscoll. Salford Royal NHS Foundation Trust, Salford, UK

We audited oxygen use amongst 443 cases brought to the "majors" A\&E area of a university hospital by NWAS ambulance teams in May-July 2010. We compared the findings with our 2007 audit conducted before publication of the BTS emergency oxygen guideline in 2008 and JRCALC guidance in 2009 (Hale K. Emerg Med J 2008;25:773).

Results $90 \%$ of cases had oximetry recorded by ambulance teams in 2007 , rising to $96 \%$ in $2010.19 \%$ of cases were hypoxic in 2010 and $27 \%$ were given oxygen compared with 34\% in 2007 (see Abstract P231 Table 1). The proportion given oxygen fell from $31 \%$ in the initial 4 weeks to $24 \%$ in the final 5 weeks of the audit when feedback was given to ambulance teams. The "ideal" figure for these cases was about $21 \%$ based on JRCALC guidance. $86 \%$ of cases were treated in accordance with JRCALC guidance in terms of receiving or not receiving oxygen and $73 \%$ were treated in full compliance (correct device and flow rate). The overall compliance rate was $4.4 \%$ higher ( $95 \%$ CI $-2.3 \%$ to $11.0 \%$ ) during the feedback period and full compliance rose by $9.9 \%$ (95\% CI 1.6 to $18.2 \%$ ) following feedback. Eight percent of cases received oxygen inappropriately and $3 \%$ were denied oxygen inappropriately. Our audit revealed that NWAS ambulance crews were unable to give controlled oxygen to COPD cases because Venturi masks were not carried. Several COPD cases received high dose oxygen from nebuliser masks throughout the journey because air driven nebulisers and nasal cannulae were not available. Only four of 14 cases with AECOPD had $\mathrm{SpO}_{2}<88 \%$ but 12 were given oxygen and 10 developed $\mathrm{SpO}_{2}>92 \%$.

\section{Abstract P231 Table 1}

\begin{tabular}{|c|c|c|c|}
\hline BTS/JRCALC Oxygen category & $\begin{array}{l}\text { Number }(\%) \\
\text { of cases }\end{array}$ & $\begin{array}{l}\text { Percent with } \\
\text { low Sp02 }\end{array}$ & $\begin{array}{l}\text { Percent given } \\
\text { oxygen }\end{array}$ \\
\hline 1. Critical illness (Reservoir mask) & $14(3 \%)$ & $50 \%$ & $79 \%$ \\
\hline 2. Moderate oxygen (Target $94-98 \%$ ) & $52(12 \%)$ & $\begin{array}{l}58 \% \\
\text { SpO2 <94\% }\end{array}$ & $71 \%$ \\
\hline 3. Controlled oxygen (Target $88-92 \%$ ) & $14(3 \%)$ & $\begin{array}{l}29 \% \\
\text { SpO2 <88\% }\end{array}$ & $86 \%$ \\
\hline 4. Give oxygen only if Sp02 falls $<94 \%$ & $363(82 \%)$ & $\begin{array}{l}12 \% \\
\text { SpO2 <94\% }\end{array}$ & $17 \%$ \\
\hline Average & $\begin{array}{l}\text { Total } 443 \\
\text { cases }\end{array}$ & $19 \%$ (86 cases) & $\begin{array}{l}27 \% \\
\text { (120 cases) }\end{array}$ \\
\hline
\end{tabular}

Conclusions The proportion of NWAS cases receiving oxygen in prehospital care has fallen from $34 \%$ in 2007 to $27 \%$ in 2010 following publication of BTS and JRCALC oxygen guidelines. $86 \%$ of cases were treated in broad compliance with JRCALC guidance and $73 \%$ were in full compliance. There is potential for further slight reduction in oxygen use in ambulances, especially for COPD patients. This may be enhanced by feedback to ambulance crews and by providing a wider range of oxygen delivery equipment in ambulances.

\section{P232 THE EARLY DETECTION OF CHRONIC OBSTRUCTIVE PULMONARY DISEASE}

doi:10.1136/thx.2010.151068.33

${ }^{1}$ A Gupta, ${ }^{2} \mathrm{~S}$ Church, ${ }^{1} \mathrm{~S}$ Lacey. ${ }^{1}$ StHealth Practice Based Commissioning Consortium, St Helens, UK; ${ }^{2}$ St Helens \& Knowsley Trust, Whiston, UK

Introduction Approximately 835000 people in England have been diagnosed with COPD however it is estimated that over 3 million have the disease ${ }^{1}$ and those cases that are diagnosed are mainly moderate or severe in nature. ${ }^{2}$ The direct cost of COPD to the UK healthcare system is estimated to be between $£ 810 \mathrm{~m}$ and $£ 930 \mathrm{~m}$ per annum $^{3}$ and without change is set to grow

Methodology It is essential that we offer good quality early diagnosis but the numbers involved are huge so a screening programme and pathway were developed. Patients at risk of COPD were initially defined as being aged over 40 with a smoking history. Vitalograph COPD6 devices, which measure $\mathrm{FEV}_{1}$ were used across 22 practices to screen the target population at an average test time of $5 \mathrm{~min}$ compared to full spirometry of $20 \mathrm{~min}$. All abnormal results were followed up with full spirometry, performed by an accredited health care provider.

Results To date 2055 patients have been screened. 841 (41\%) demonstrated an abnormal result on COPD6 screening. Of these so far 376 have had COPD confirmed by spirometry. That is $18.3 \%$ of the target population and $45 \%$ of the group who had abnormal COPD6 results. It is estimated that, nationally over 2 million people have undiagnosed COPD and of those over $50 \%$ are diagnosed with moderate to severe disease ${ }^{2}$ however the results available to date suggest that early detection leads to the majority of patients being identified while their condition is still mild. Results to date demonstrate that $75 \%$ of diagnoses were mild, $18 \%$ moderate and $3.2 \%$ severe. We are still awaiting confirmation of the remaining $3.8 \%$. The project is ongoing.

Outcomes Mild COPD costs approximately 50\% less to treat than moderate COPD and $90 \%$ less than severe COPD. ${ }^{4}$ Therefore in addition to improving outcomes for patients, early detection will also reduce the burden of care to the NHS and socioeconomic costs.

\section{REFERENCES}

1. Consultation on a Strategy for Services for Chronic Obstructive Pulmonary Disease (COPD) in England ${ }^{50}$.

2. Consultation on a Strategy for Services for Chronic Obstructive Pulmonary Disease (COPD) in England ${ }^{15}$.

3. Consultation on a Strategy for Services for Chronic Obstructive Pulmonary Disease (COPD) in England ${ }^{14}$

4. NICE-Chronic obstructive pulmonary disease: Management of chronic obstructive pulmonary disease in adults in primary and secondary care.

\section{P233 COPD AND ME: THE DEVELOPMENT AND IMPLEMENTATION OF AN INDIVIDUAL PATIENT MANAGEMENT PLAN AND HAND-HELD RECORD}

doi:10.1136/thx.2010.151068.34

${ }^{1} \mathrm{~T}$ Robinson, ${ }^{1} \mathrm{~S}$ Shires, ${ }^{2} \mathrm{C}$ Fletcher, ${ }^{2} \mathrm{~J}$ Parrington, ${ }^{2} \mathrm{~J}$ Norell, ${ }^{2} \mathrm{~S}$ Mabbett. ${ }^{1}$ Harrogate and District NHS Foundation Trust, $N$ Yorks, UK; ${ }^{2}$ NHS North Yorkshire and York, N Yorks, UK

Background People with chronic obstructive pulmonary disease (COPD) face multiple challenges living with a progressive and 